\title{
Thrombospondin Mediates Migration and Potentiates Platelet-Derived Growth Factor-Dependent Migration of Calf Pulmonary Artery Smooth Muscle Cells
}

\author{
RACHEL YABKOWITZ,* PAMELA J. MANSFIELD, UNA S. RYAN, AND \\ SUZANNE J. SUCHARD
}

Departments of Pathology (R.Y.) and Pediatrics (P.J.M., S.J.S.), University of Michigan School of Medicine, Ann Arbor, Michigan 48109, and Department of Surgery (U.S.R.), Washington University, St. Louis, Missouri 63110

\begin{abstract}
A precipitating factor in the development of atherosclerotic lesions is the inappropriate migration and proliferation of vascular smooth muscle cells (SMC) within the intima of the vessel wall. Focusing on the role of extracellular matrix proteins in SMC migration, we have demonstrated that thrombospondin (TSP) itself is a potent modulator of SMC motility and acts to potentiate platelet-derived growth factor (PDGF)-mediated SMC migration as well. Migration of SMC to TSP was dose dependent. Interestingly, maximal SMC migration to TSP exceeded that to either PDGF or basic fibroblast growth factor (bFGF). The distal $\mathrm{COOH}$ terminus of TSP was shown to mediate SMC migration as demonstrated by complete inhibition of the response by monoclonal antibody (mAb) C6.7. Nevertheless, proteolytic fragments of TSP were not as potent as intact TSP in mediating SMC migration. Only by combining the heparin-binding domain (HBD) with the $140 \mathrm{kD}$ $\mathrm{COOH}$ terminal fragment was SMC migration restored to levels seen with intact TSP. Based on antibody inhibition studies, an $\alpha_{v}$-containing integrin receptor, but not $\alpha_{v} \beta_{1}$ or $\alpha_{v} \beta_{3}$, appeared to be involved in SMC migration to TSP. The coincidental expression of PDGF and TSP at sites of vascular injury and inflammation led us to evaluate the effect of suboptimal levels of TSP on SMC responsiveness to PDGF. SMC migration in response to PDGF was enhanced nearly $60 \%$ in the presence of suboptimal concentrations of TSP. This effect was specific for PDCF and dependent on the concentration of TSP with maximal potentiation obtained between 50-100 nM TSP, concentrations tenfold lower than those necessary for SMC migration to TSP itself. mAb C6.7 completely inhibited enhancement but, as with SMC migration to TSP alone, TSP proteolytic fragments did not possess the effectiveness of the intact molecule. Additional experiments assessing SMC migration to PDGF demonstrated that PDGF stimulated SMC motility indirectly by inducing TSP synthesis. These studies suggested that TSP functions as an autocrine motility factor to modulate SMC migration, which in conjunction with PDGF could serve to aggravate and accelerate development of atherosclerotic lesions at sites of vascular injury or inflammation. (c) 1993 Wilcy-Liss, Inc.
\end{abstract}

Migration of smooth muscle cells (SMC) into the vascular intima and their inappropriate proliferation are thought to contribute to the pathology of atherosclerosis (Ross, 1986). These functional changes correlate with the modulation of the SMC phenotype from a quiescent, contractile state to a synthetic, proliferative state (Chamley-Campbell et al., 1981). Therefore, the signals that stimulate SMC migration and proliferation have been intensively studied in order to identify relevant pathways and possible nodes of intervention.

One of the most potent modulators of SMC migration and proliferation is platelet-derived growth factor (PDGF) (Ross et al., 1986). PDGF is secreted by activated platelets and macrophages, among several other cell types, at sites of inflammation and vascular dam- age. Proliferation of quiescent SMC is stimulated within 24 hours after exposure to PDGF (Majack et al., 1990). Similarly, SMC migration to PDGF has been demonstrated in vitro and, in vivo, PDGF is believed to mediate SMC migration into the neointima (Grotendorst et al., 1982; Clowes and Clowes, 1986). Overall, these profound effects on SMC physiology implicate PDGF as a major factor in the propagation of atherosclerotic lesions.

Received December 7, 1992; accepted May 17, 1993.

*To whom reprint requests/correspondence should be addressed at Amgen, Inc., Amgen Center, 1840 DeHavilland Dr., Thousand Oaks, California 91320-1789. 
Less well studied is the involvement of extracellular matrix (ECM) molecules in SMC behavior. While SMC adhere to ECM components such as fibronectin, collagen, thrombospondin (TSP), and laminin, less is known about the role of ECM in SMC proliferation and migration (Hedin et al., 1988; Lawler et al., 1988). Recent reports have demonstrated migration of SMC to fibrinogen and vitronectin, two ECM molecules that are abundant in plasma (Naito et al., 1989, 1991). In addition, immunohistochemical analysis has localized high concentrations of fibronectin, collagen, and TSP at sites of atherosclerotic lesions and vascular injury (Raugi et al., 1990; Shekhonin et al., 1987) suggesting that, in vivo, these ECM components are localized in regions of active SMC proliferation and migration.

TSP is unique among ECM proteins in that its concentration in the plasma is fairly low. However, TSP expression increases rapidly and transiently following tissue damage and platelet activation (Mosher, 1990; Lawler, 1986). Besides platelets, TSP is also secreted by SMC, monocytes, endothelial cells, and fibroblasts. Within 30 minutes of PDGF stimulation TSP mRNA levels in SMC rise dramatically followed by an increase in protein levels within 2 hours (Majack et al., 1985, 1987). The kinetics of TSP mRNA induction and its independence of protein synthesis suggested that TSP is a member of the immediate-early response gene family whose members include fos and myc. The ability of TSP to modulate SMC proliferation, essentially acting as an autocrine growth factor for SMC, was demonstrated in two respects. First, TSP potentiates epidermal growth factor (EGF)-dependent mitogenesis (Majack et al., 1986). Second, TSP was shown to be essential for the proliferative response of SMC to PDGF (Majack et al., 1988). These studies demonstrate that TSP is an important modulator of SMC function, and through its restricted pattern of expression in damaged tissue, may play a role in the progression of atherosclerotic lesions.

We have investigated the effect of TSP on SMC motility and have found TSP to be a potent stimulator of SMC migration. Additionally, we found that PDGF and TSP acted synergistically in stimulating migration. These data highlight not only the complex interactions between cells and extracellular signals involved in SMC physiology, but also suggest that the role of ECM proteins may be more integrative than previously realized.

\section{MATERIALS AND METHODS Materials}

TSP and TSP fragments were isolated and purified from activated platelets as previously described (Dixit et al., 1984; Yabkowitz and Dixit, 1991). Platelet TSP is thought to be a TSP1 homotrimer (LaBell et al., 1992). The $70 \mathrm{kD}$ core fragment of TSP was produced by chymotrypsin cleavage of the $140 \mathrm{kD}$ fragment (1:100 wt/ wt) in the presence of $5 \mathrm{mM}$ ethylenediaminetetraacetic acid (EDTA) for 2 hours at $37^{\circ} \mathrm{C}$ followed by fractionation over a heparin-Sepharose column. The 70 $\mathrm{kD}$ fragment was recovered in the flowthrough fractions. Intact TSP was also chymotrypsinized (1:100, wt/ wt) for 40 minutes at $37^{\circ} \mathrm{C}$ and used without further fractionation (Mansfield et al., 1990). Homogeneity of
TSP and TSP fragments was judged by sodium dodecyl sulfate polyacrylamide gel electrophoresis (SDSPAGE) analysis to be $>95 \%$. Human PDGF-BB and bFGF were generous gifts from Amgen (Thousand Oaks, CA) and Synergen (Boulder, CO), respectively. TSP-specific monoclonal antibodies (mAbs) have been previously described and characterized (Dixit et al., 1986). The synthetic peptides GRGDS and GRGES were purchased from Calbiochem (La Jolla, CA) and Penninsula Labs (Belmont, CA), respectively, and were tested at a concentration of $1 \mathrm{mM}$. Heparin was purchased from Sigma (St. Louis, MO). Mouse IgG was purchased from Cappel (Malvern, PA) and used at a concentration of $20 \mu \mathrm{g} / \mathrm{ml}$. Antibodies against cell surface receptors were obtained as follows: mAbs LM142 and LM609 (both used at a dilution of 1:5) were gifts of Dr. David Cheresh (Scripps Clinic, La Jolla, CA); mAb AIIB2 specific for the $\beta_{1}$ integrin subunit (used at a 1:5 dilution) was a gift of Dr. Caroline Damsky (University of California, San Francisco, CA); mAbs SZ21 specific for the $\beta_{3}$ integrin subunit and FA6.152 specific for GPIV (both used at $20 \mu \mathrm{g} / \mathrm{ml}$ ) were purchased from AMAC (Westbrook, ME); mAb 30 specific for GPIV (used at $5 \mu \mathrm{g} / \mathrm{ml}$ ) was a gift of Dr. Graham Jamieson (American Red Cross, Rockville, MD); mAb OKM5 also specific for GPIV (used at $5 \mu \mathrm{g} / \mathrm{ml}$ ) was purchased from Ortho Diagnostics (Raritan, NJ).

\section{Cells}

Bovine pulmonary artery SMC were isolated and characterized as described (Ryan and Maxwell, 1992) and used between passages 2 and 10. Cells were grown in Dulbecco's modified eagle's medium (DMEM) containing $10 \%$ fetal bovine serum (FBS), nonessential amino acids, $1 \mathrm{mM}$ sodium pyruvate, $100 \mathrm{U} / \mathrm{ml}$ penicillin, $100 \mu \mathrm{g} / \mathrm{ml}$ streptomycin, and $250 \mu \mathrm{g} / \mathrm{ml}$ gentamicin. Confluent SMC were subcultured at $1: 3$ or $1: 4$ as needed. SMC were harvested at $80 \%$ confluency by incubation in phosphate-buffered saline (PBS) containing $1 \mathrm{mM}$ EDTA for 3 minutes followed by pipetting cells off the plates. Pooled cells were washed three times in DMEM and allowed to recover for 30 minutes at room temperature before treatment.

\section{Chemotaxis assays}

Assays were carried out in 48-well chambers (Neuroprobe, Cabin John, MD) using $8 \mu \mathrm{m}$ polycarbonate filters (Nuclepore, Pleasanton, CA) essentially as described (Mansfield et al., 1990; Yabkowitz et al., 1993). Filters were soaked overnight in $100 \mu \mathrm{g} / \mathrm{ml}$ gelatin in $0.1 \%$ acetic acid at $37^{\circ} \mathrm{C}$ to allow the initial attachment of cells (Taraboletti et al., 1987). TSP, TSP fragments, or growth factors were diluted in DMEM plus $0.1 \%$ bovine serum albumin (BSA) and added to the lower wells of the chamber. SMC $\left(3 \times 10^{4} /\right.$ well $)$ in the same buffer were added to the upper well of the chamber and the assembled chamber incubated for 6 hours at $37^{\circ} \mathrm{C}$. Filters were fixed and stained with hematoxylin. Three filters were used for each treatment and five fields were scored from each filter under high power magnification $(\times 400)$. Data were expressed as mean number SMC migrating per field \pm S.E.M. Buffer alone in the lower well served as a negative control $(0.5 \pm 0.3 \mathrm{SMC} /$ field). Where appropriate, statistical analysis for sig- 
nificance was performed using a one-tailed paired Student's t-test. For inhibition experiments, TSP was preincubated with anti-TSP mAbs for 30 minutes at $37^{\circ} \mathrm{C}$, or SMC were preincubated with mAbs against cell surface receptors or synthetic peptides for $30 \mathrm{~min}$ utes at room temperature before being added to the lower or upper wells of the chamber, respectively. In experiments where chemoattractants were combined, no preincubation was necessary; the individual components were added directly to the lower wells. For cycloheximide and $\mathrm{mAb}$ C6.7 experiments, SMC were preincubated for 16 hours or 30 minutes, respectively, before addition to the upper wells of chemotaxis chambers. Cycloheximide $(10 \mu \mathrm{g} / \mathrm{ml})$ or $\mathrm{mAb} \mathrm{C} 6.7$ was also present throughout the assay period. Treated SMC were evaluated for chemotaxis to either $10 \mathrm{ng} / \mathrm{ml}$ PDGF or $1 \mu \mathrm{M}$ TSP as described above. All experiments were repeated two to three times.

\section{RESULTS \\ SMC chemotaxis to TSP}

Pulmonary artery SMC demonstrated dose-dependent migration to soluble TSP with a linear increase between 30 and $200 \mathrm{nM}$ TSP and a maximal response seen at approximately $1 \mu \mathrm{M}$ (Fig. 1a). Directionality of migration (chemotaxis) was established by comparing the response of SMC to TSP placed in either the upper or lower wells; whereas SMC migration to TSP placed in the lower wells was significant, no migration above background was evident when TSP was present in the upper wells (data not shown). We compared the response of SMC to TSP to the responses of SMC to two other well characterized chemoattractants, PDGF-BB and bFGF (Grotendorst et al., 1982; Sato et al., 1991). At their maximal effective concentrations, TSP, on average, elicited a $40 \%$ higher response than either PDGF or bFGF (Fig. 1b).

To rule out the possibility that transforming growth factor beta (TGF- $\beta$ ) contamination of our TSP preparations was responsible for the migratory effects observed with SMC (Murphy-Ullrich et al., 1992), we used both a neutralizing anti-TGF- $\beta$ antibody and purified recombinant TGF- $\beta$. In one set of assays, TSP was preincubated with varying concentrations of anti-TGF- $\beta$ antibody (up to $100 \mu \mathrm{g} / \mathrm{ml}$ ) before addition to the lower wells of chemotaxis chambers. No effect on SMC chemotaxis to TSP was observed over the range of antibody concentrations tested (data not shown). Additionally, spiking our TSP preparations with $0.01-100 \mathrm{ng} / \mathrm{ml} \mathrm{re}-$ combinant TGF- $\beta$ did not alter SMC chemotaxis to TSP (data not shown). These results indicated that TSPmediated SMC chemotaxis was not a result of TGF- $\beta$ contamination, but represented a TSP-specific response.

To further demonstrate specificity and determine which domain of the TSP molecule mediated SMC migration, anti-TSP mAbs were screened for inhibition of migration. mAb C6.7, specific for the distal $\mathrm{COOH}$ terminus, inhibited SMC migration to TSP (Fig. 2). None of the other mAbs tested, including mAb A2.5 directed against the heparin-binding domain (HBD), inhibited SMC migration. Interestingly, heparin inhibited SMC migration slightly, by approximately $20 \%$. In contrast, another sulfated oligosaccharide, dermatan sulfate, did
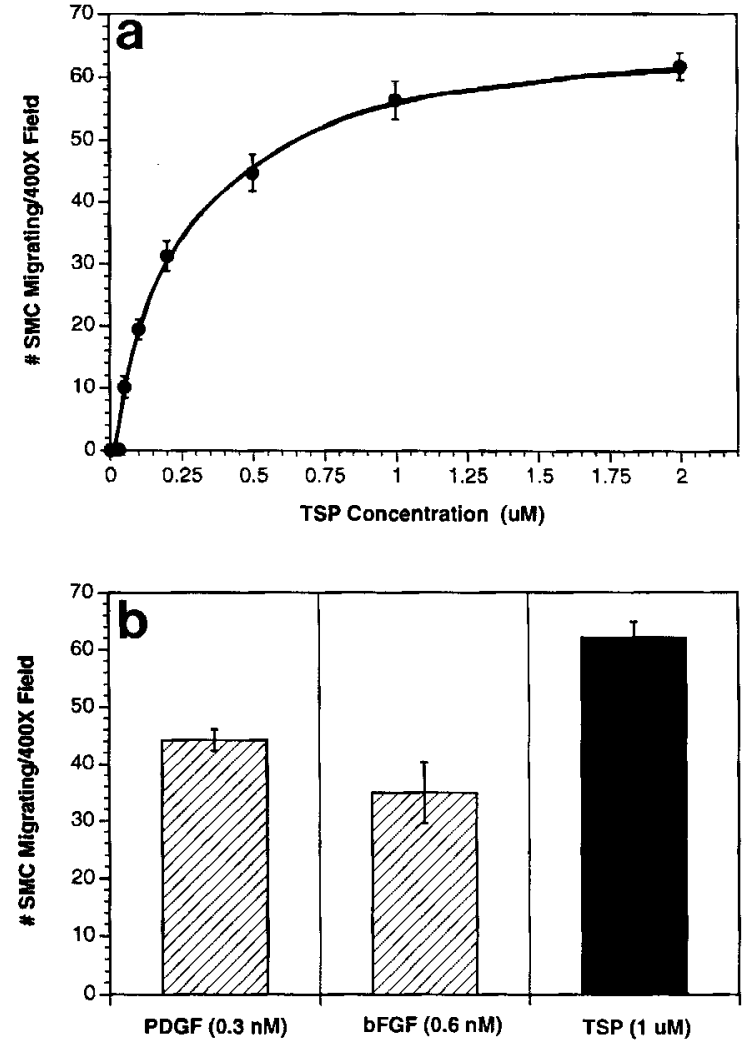

Fig. 1. TSP mediates calf pulmonary artery SMC migration. a: SMC migration to TSP is dose dependent. b: Comparison of SMC migration to PDGF, bFGF, and TSP. SMC $\left(3 \times 10^{4} /\right.$ well $)$ were placed into the upper wells of modified Boyden chambers and the indicated concentrations of TSP, PDGF, or bFGF were added to the lower wells. Assays were carried out for 6 hours at $37^{\circ} \mathrm{C}$. The number of migrating SMC was scored as described in Materials and Methods with triplicate filters prepared for each concentration. Five high power $(\times 400)$ fields were scored for each filter and values shown represent the mean \pm S.E.M. The number of migrating cells/field was comparable between triplicate filters in any experiment. For example, the range of SMC migration to $1 \mu \mathrm{M}$ TSP was $54-72,53-71$, and 59-74 SMC/field in the triplicate filters assayed in a single experiment. SMC responses to PDGF-BB, bFGF, or TSP were compared at the concentration determined to elicit maximal SMC migration in each case; specifically 0.3 $\mathrm{nM}(10 \mathrm{ng} / \mathrm{ml})$ PDGF, $0.6 \mathrm{nM}(10 \mathrm{ng} / \mathrm{ml}) \mathrm{bFGF}$, or $1 \mu \mathrm{M}$ TSP.

not inhibit SMC migration (data not shown). Mouse IgG had no effect (data not shown). Inhibition of migration by mAb C6.7 was dose dependent with partial inhibition evident at $50 \mu \mathrm{g} / \mathrm{ml}$ antibody and virtually complete inhibition at $200 \mu \mathrm{g} / \mathrm{ml}$ (Table 1 ).

To further define the TSP domain(s) involved in mediating SMC chemotaxis, assays were also conducted with TSP proteolytic fragments. Surprisingly, no proteolytic fragment retained the potency of intact TSP in mediating SMC migration (Fig. 3). The $140 \mathrm{kD}$ fragment (140K), containing the mAb C6.7 epitope, partially supported SMC chemotaxis with a maximal response approximately $50 \%$ of that seen with intact TSP. SMC migration to $140 \mathrm{~K}$ was dose dependent, similar to that observed with intact TSP, with a maximal effect observed at $1 \mu \mathrm{M}$ (data not shown). Both the HBD and the $70 \mathrm{kD}$ core region, derived from the $140 \mathrm{kD}$ fragment, supported a minimal level of SMC migration, at 


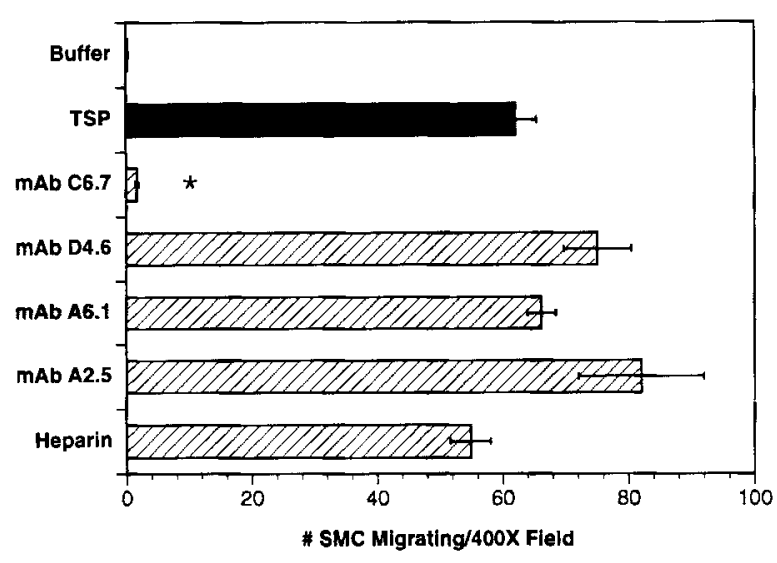

Fig. 2. Migration of SMC to TSP is inhibited by anti-TSP mAb C6.7. $\mathrm{TSP}(1 \mu \mathrm{M})$ was preincubated in the presence or absence of anti-TSP $\mathrm{mAbs}(200 \mu \mathrm{g} / \mathrm{ml})$ or heparin $(100 \mu \mathrm{g} / \mathrm{ml})$ for 30 minutes at $37^{\circ} \mathrm{C}$ before being placed in the lower wells of modified Boyden chambers. SMC $\left(3 \times 10^{4} /\right.$ well $)$ were placed in the upper wells and the assay carried out for 6 hours at $37^{\circ} \mathrm{C}$. The number of migrating SMC was scored as described in Materials and Methods with triplicate filters prepared for each treatment. Five high power $(\times 400)$ fields were scored for each filter and values shown represent the mean \pm S.E.M. ${ }^{*} P<0.01$.

TABLE 1. Inhibition of SMC chemotaxis to TSP by mAb C6.7 is dose dependent

\begin{tabular}{lcc}
\hline Treatment & $\begin{array}{c}\text { mAb concentration } \\
(\mu \mathrm{g} / \mathrm{ml})\end{array}$ & $\begin{array}{c}\text { Migratory response } \\
\text { \#SMC/field } \pm \text { S.E.M. }\end{array}$ \\
\hline Buffer & - & $0.5 \pm 0.3$ \\
TSP & - & $61.3 \pm 4.6$ \\
mAb C6.7 & 20 & $62.8 \pm 2.0$ \\
& 50 & $33.2 \pm 1.3$ \\
& 75 & $7.7 \pm 4.0$ \\
& 200 & $0.5 \pm 0.1$ \\
\hline
\end{tabular}

${ }^{1} \mathrm{TSP}(1 \mu \mathrm{M})$ was preincubated in the presence or absence of the indicated concentrations of $\mathrm{mAb}$ C6.7 for 30 minutes at $37^{\circ} \mathrm{C}$ before being placed into the lower wells of a modified Boyden chamber. SMC $\left(3 \times 10^{4}\right)$ were placed in each upper well and the assay carried out for 6 hours at $37^{\circ} \mathrm{C}$. The number of migrating SMC was scored as described in Materials and Methods with triplicate filters prepared for each treatment. Five high power $(\times 400)$ fields were scored for each filter and values shown represent the mean \pm S.E.M

most $10 \%$ of the response to intact TSP. In contrast, the combination of the HBD and $140 \mathrm{~K}$ was almost as potent as intact TSP (Fig. 3). The chemotactic response was significantly greater $(P<0.05)$ than the calculated additive effect of the HBD and $140 \mathrm{~K}$ individually. Although the HBD itself was relatively ineffective in supporting SMC migration, it appeared to enhance SMC migration to $140 \mathrm{~K}$. This enhanced response was consistently observed among several different batches of both the HBD and $140 \mathrm{~K}$.

SMC chemotaxis to $140 \mathrm{~K}$ and the combination of $140 \mathrm{~K}$ and the HBD was further evaluated in the presence of anti-TSP mAbs (Table 2). mAb C6.7 inhibited migration of SMC to either $140 \mathrm{~K}$ or the HBD/140K mixture by approximately $50 \%$. Interestingly, heparin inhibited SMC migration to either $140 \mathrm{~K}$ or the HBD/ $140 \mathrm{~K}$ mixture equivalently, by about $20 \%$, suggesting that heparin may be interacting with a site on $140 \mathrm{~K}$. This possibility was confirmed by assessing SMC migration in the presence of both heparin and $\mathrm{mAb}$ C6.7; in the presence of both reagents, $\mathrm{SMC}$ migration to

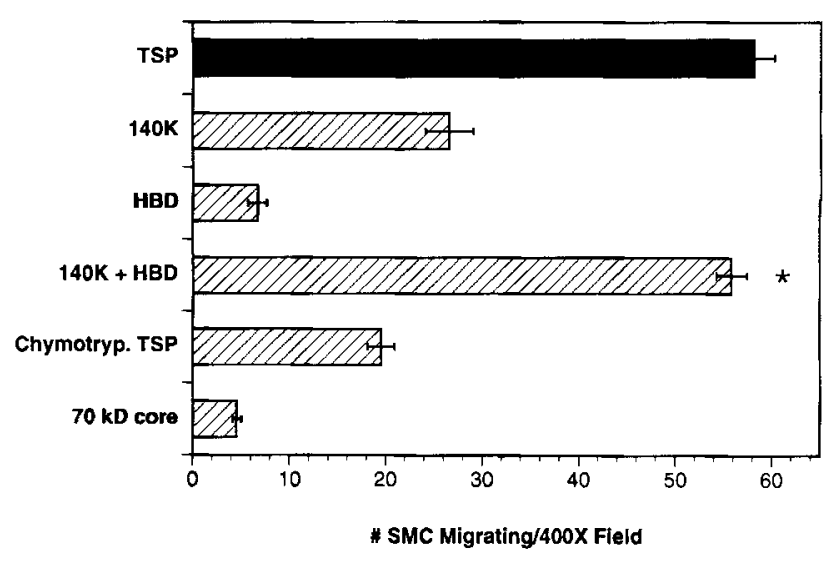

Fig. 3. Migration of SMC is partially supported by TSP proteolytic fragments but fully restored by a combination of the $\mathrm{HBD}$ and $140 \mathrm{~K}$. SMC $\left(3 \times 10^{4} /\right.$ well $)$ were placed into the upper wells of modified Boyden chambers. TSP or TSP proteolytic fragments $(1 \mu \mathrm{M})$ were added to the lower wells and assays carried out for 6 hours at $37^{\circ} \mathrm{C}$. The number of migrating SMC was scored as described in Materials and Methods with triplicate filters prepared for each treatment. Five high power $(\times 400)$ fields were scored for each filter and values shown represent the mean \pm S.E.M. ${ }^{*} P<0.05$, migration of SMC in response to a mixture of the HBD and $140 \mathrm{~K}$ was compared to SMC migration in response to the calculated additive effect of the fragments individually.

either $140 \mathrm{~K}$ or the $\mathrm{HBD} / 140 \mathrm{~K}$ mixture decreased to nearly background levels, thereby suggesting that cooperative interactions between two sites on TSP may be involved. Furthermore, mAb A2.5 did not inhibit SMC migration to the $\mathrm{HBD} / 140 \mathrm{~K}$ mixture, reinforcing the likelihood that a heparin-binding site within $140 \mathrm{~K}$ was involved. Thus, the priming effect of the HBD on SMC chemotaxis to $140 \mathrm{~K}$ may involve conformational changes in the $140 \mathrm{kD}$ domain driven by its interaction with the HBD.

\section{SMC receptors involved in TSP-mediated chemotaxis}

Several distinct cell surface molecules, including $\alpha_{v} \beta_{3}$ integrins and GPIV (CD36), have been shown to serve as TSP receptors on a variety of cell types (Lawler et al., 1988; Asch et al., 1987). We, therefore, tested antibodies to these molecules to determine whether these receptors mediated the migration of SMC to TSP. MAb LM142, specific for the $\alpha_{v}$ subunit of the $\alpha_{v} \beta_{3}$ vitronectin receptor (Cheresh and Spiro, 1987), partially inhibited SMC migration (Fig. 4). At $200 \mu \mathrm{g} / \mathrm{ml}$ mAb LM142 inhibited migration by about $60 \%$ $(P<0.05)$. Interestingly, the same concentration of mAb L.M609, specific for the $\alpha_{v} \beta_{3}$ complex (Cheresh and Spiro, 1987), did not significantly inhibit migration. In contrast, SMC chemotaxis to $1 \mu \mathrm{M}$ vitronectin $(15.8 \pm 1.0 \mathrm{SMC} /$ field) was reduced by $70 \%(4.7 \pm 0.6$ $\mathrm{SMC} /$ field) in the presence of $200 \mu \mathrm{g} / \mathrm{ml} \mathrm{mAb} \mathrm{LM609.}$ These data suggested that the $\alpha_{v}$ subunit was mediating SMC migration through its association with an alternative $\beta$ subunit. However, antibodies to the $\beta_{1}$ and $\beta_{3}$ subunits did not significantly inhibit migration. Additionally, the synthetic peptides GRGDS and GRGES failed to significantly inhibit SMC migration, indicating that the RGD amino acid sequence in TSP was not involved in SMC migration to TSP. Similarly, three 
TABLE 2. Inhibition of SMC migration to TSP fragments

\begin{tabular}{llcc}
\hline Attractant & \multicolumn{1}{c}{ Inhibitor } & Concentration & \% Control $( \pm$ SEM $)$ \\
\hline $140 \mathrm{~K}$ & None & - & $100.0^{1}$ \\
& mAb C6.7 & $100 \mu \mathrm{g} / \mathrm{ml}$ & $47.6( \pm 5.1)$ \\
& mAb A2.5 & $100 \mu \mathrm{g} / \mathrm{ml}$ & $109.4( \pm 3.9)$ \\
& Heparin & $100 \mu \mathrm{g} / \mathrm{ml}$ & $86.0( \pm 12.1)$ \\
$140 \mathrm{~K}+\mathrm{HBD}$ & $100 \mu \mathrm{g} / \mathrm{ml}$ each & $6.0( \pm 6.5)$ \\
& mAb C6.7 + heparin & $100 \mu \mathrm{g} / \mathrm{ml}$ & 100.0 \\
& None & $100 \mu \mathrm{g} / \mathrm{ml}$ & $56.1( \pm 9.3)$ \\
& mAb C6.7 & $100 \mu \mathrm{g} / \mathrm{ml}$ & $109.6( \pm 5.2)$ \\
& mAb A6.1 & $100 \mu \mathrm{g} / \mathrm{ml}$ & $108.2( \pm 1.8)$ \\
& mAb A2.5 & $100 \mu \mathrm{g} / \mathrm{ml}$ each & $81.8( \pm 8.9)$ \\
& Heparin & $7.8( \pm 1.0)$ \\
\hline
\end{tabular}

${ }_{1}^{1} 140 \mathrm{~K}$ or $140 \mathrm{~K}+\mathrm{HBD}(1 \mu \mathrm{M})$ were preincubated with the indicated concentrations of mAbs or heparin for 30 minutes at $37^{\circ} \mathrm{C}$ before being placed into the lower wells of a modified Boyden chamber. SMC $\left(3 \times 10^{4} /\right.$ well $)$ were placed into the upper wells and the assay carried out for 6 hours at $37^{\circ} \mathrm{C}$. The number of migrating SMC was scored as deseribed in Materials and Methods with triplicate filters prepared for each treatment. Five high power $(\times 400)$ fields were scored for each filter and values shown represent the mean \% control \pm S.E.M. Control samples represented SMC migration to $1 \mu M 140 \mathrm{~K}$ or $140 \mathrm{~K}+\mathrm{HBD}$ in the absence of antibody.

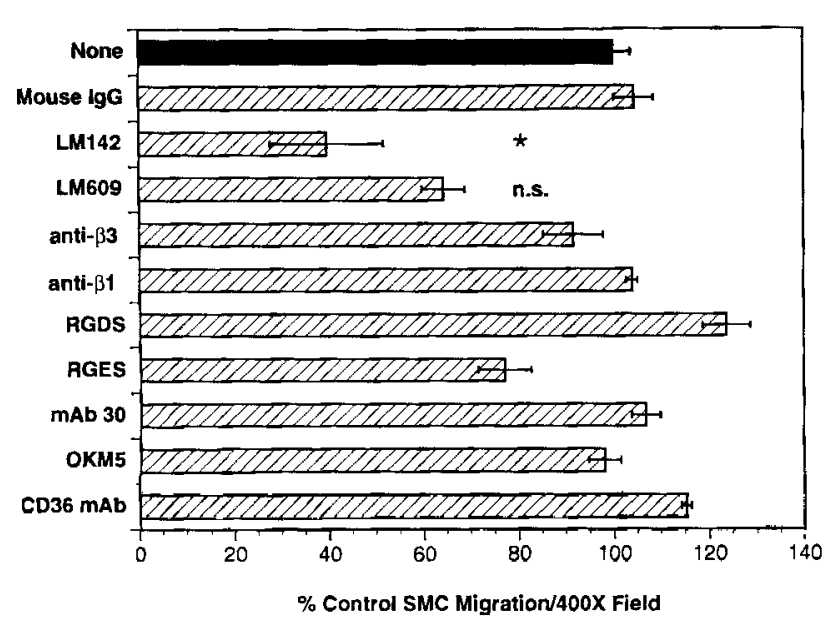

Fig. 4. SMC migration to TSP is inhibited by antibodies to the $\alpha_{\mathrm{v}}$ subunit of integrin receptors. SMC $\left(3 \times 10^{4} /\right.$ well $)$ were preincubated in the presence or absence of the indicated antibodies, mouse IgG, or the synthetic peptides GRGDS or GRGES for 30 minutes at room temperature before being added to the upper wells of modified Boyden chambers. TSP $(1 \mu \mathrm{M})$ was present in the lower wells of all samples. Migration assays were carried out for 6 hours at $37^{\circ} \mathrm{C}$. The number of migrating SMC was scored as described in Materials and Methods with triplicate filters prepared for each treatment. Five high power $(\times 400)$ fields were scored for each filter and values shown represent the mean \% control \pm S.E.M. Control samples represented SMC migration to $1 \mu \mathrm{M}$ TSP in the absence of antibody and averaged $56.8 \pm 2.1 \mathrm{SMC} / 400 \times$ field. ${ }^{*} P<0.05 . \mathrm{n.s} .=$ not significant.

different mAbs directed against GPIV had no effect on SMC migration. These results revealed that the $\alpha_{\mathrm{v}}$ integrin subunit associated with a $\beta$ subunit other than $\beta_{1}$ or $\beta_{3}$ is important in the migratory response of SMC to TSP. Furthermore, the lack of complete inhibition by $\alpha_{\mathrm{v}}$ specific antibodies suggested that another SMC receptor may also be involved in mediating SMC migration to TSP.

\section{TSP potentiates PDGF-mediated SMC chemotaxis}

TSP mRNA levels increase within 30 minutes of PDGF stimulation of SMC and, subsequently, TSP expression increases within 2 hours (Majack et al., 1985, 1987). Therefore, within this short time frame after

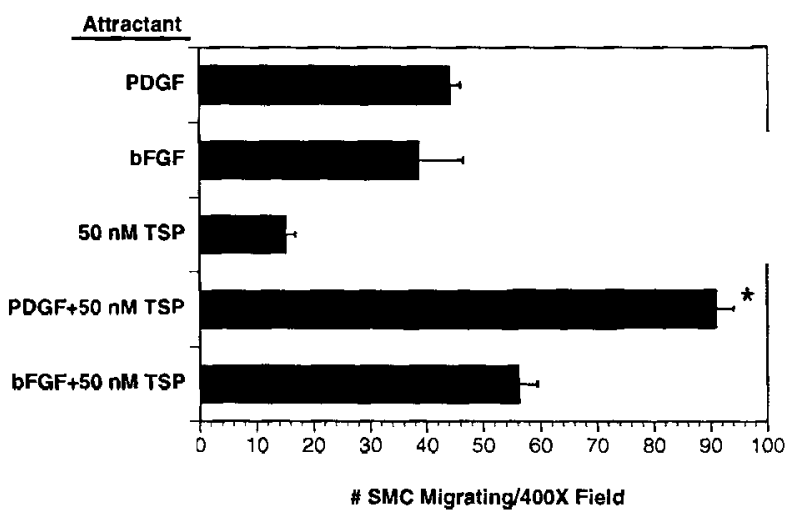

Fig. 5. TSP potentiates SMC migration to PDGF. SMC $\left(3 \times 10^{4} /\right.$ well $)$ were placed in the upper wells of modified Boyden chambers. PDGF $(10 \mathrm{ng} / \mathrm{ml})$, bFGF $(10 \mathrm{ng} / \mathrm{ml})$, TSP $(50 \mathrm{nM})$, or a mixture of TSP and either PDGF or bFGF was placed into the lower wells and SMC migration allowed to proceed for 6 hours at $37^{\circ} \mathrm{C}$. The number of migrating SMC was scored as described in Materials and Methods with triplicate filters prepared for each treatment. Five high power $(\times 400)$ fields were scored for each filter and values shown represent the mean \pm S.E.M. ${ }^{*} P<0.025$, migration of SMC in response to a mixture of PDGF and $50 \mathrm{nM}$ TSP was compared to SMC migration in response to the calculated additive effect of each attractant individually.

PDGF stimulation, the extracellular environment contains both PDGF and TSP; each of which can stimulate SMC migration. It was therefore of interest to determine whether PDGF and TSP together would affect SMC migration differently than either molecule alone. In the presence of suboptimal concentrations of TSP, SMC motility to PDGF was increased significantly, $P<0.025$, above the calculated additive response of SMC to each attractant individually (Fig. 5). This effect was specific for PDGF, since the addition of suboptimal concentrations of TSP to bFGF did not elicit similar potentiation. The enhancing effect of TSP on PDGF. mediated migration was consistent among different batches of TSP and PDGF. Furthermore, the potentiation of SMC motility was dependent on TSP concentration (Fig. 6), with the extent of potentiation increasing as the concentration of TSP increased. In the presence of $50 \mathrm{nM}$ TSP SMC migration was about $50 \%$ higher than the calculated additive response of SMC to each 


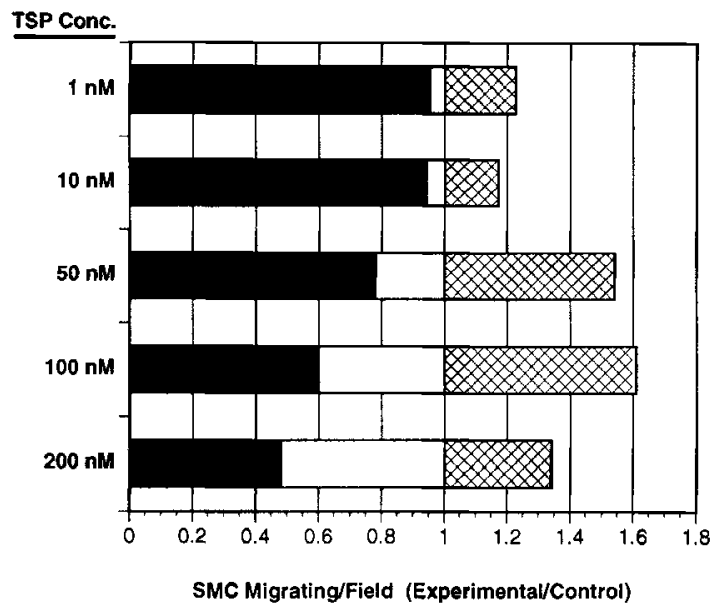

Fig. 6. TSP potentiation of SMC migration to PDGF is dose dependent. SMC $\left(3 \times 10^{4} /\right.$ well $)$ were placed in the upper wells of modified Boyden chambers. PDGF (10 $\mathrm{ng} / \mathrm{ml}$ ) and the indicated concentrations of TSP were combined and placed into the lower wells. SMC migration was allowed to proceed for 6 hours at $37^{\circ} \mathrm{C}$. The number of migrating SMC was scored as described in Materials and Methods with triplicate filters prepared for each treatment. Five high power $(\times 400)$ fields were scored for each filter and values shown represent the mean ratio of experimental to control SMC migration. Control migration represents the calculated additive effect of PDGF and TSP assayed individ ually, with the fraction due to PDGF ( $\square$ ) and TSP ( $\square$ ) indicated. Experimental migration represents the observed effect on SMC migration of the mixture of PDGF and TSP together. The fraction of the response to the mixture of PDGF and TSP accounting for the potentiation effect of TSP is indicated $(\otimes)$.

attractant. Peak enhancement of PDGF-mediated migration was seen at $100 \mathrm{nM}$ TSP, approximately a $60 \%$ increase, with higher concentrations of TSP inducing less of a response. Overall, SMC migration to the combination of PDGF and TSP was greater than migration to either $10 \mathrm{ng} / \mathrm{ml}$ PDGF or $1 \mu \mathrm{M}$ TSP, concentrations that yielded maximal migration.

As with SMC migration to TSP alone, anti-TSP mAbs were used to determine which domain of TSP mediated the enhancement of PDGF-mediated SMC migration (Fig. 7a). In the presence of $75 \mu \mathrm{g} / \mathrm{ml} \mathrm{mAb} \mathrm{C6.7} \mathrm{motility}$ decreased by about $80 \%$; at $200 \mu \mathrm{g} / \mathrm{ml} \mathrm{mAb} \mathrm{C6.7} \mathrm{the}$ response was completely abolished. The ability of $\mathrm{mAb}$ C6.7 to completely inhibit migration to the combination of $50 \mathrm{nM}$ TSP and PDGF was surprising, considering that PDGF is typically a strong stimulus for SMC migration, and suggested that specific interactions between the two molecules might be responsible. Otherwise, an antibody against TSP would not be capable of knocking out the response to PDGF as well. None of the other TSP-specific mAbs were inhibitory.

Since the $140 \mathrm{kD}$ fragment of TSP partially supported SMC migration, we evaluated its effectiveness at suboptimal concentrations in potentiating migration to PDGF (Fig. 7b). Neither 140K nor the HBD potentiated SMC migration above the calculated additive response. Based on the evidence that the HBD enhanced SMC migration to $140 \mathrm{~K}$, we also looked at whether a combination of the $\mathrm{HBD}$ and $140 \mathrm{~K}$ would potentiate SMC migration to PDGF. This was not the case; indeed the migratory responses to the combination of PDGF,
$140 \mathrm{~K}$, and the HBD were similar to the responses observed with PDGF and either fragment alone. Thus, it appeared that potentiation of SMC migration to PDGF mediated by suboptimal concentrations of TSP could only be elicited by intact TSP.

Complete inhibition by mAb C6.7 of SMC chemotaxis to the combination of $50 \mathrm{nM}$ TSP and PDGF suggested that PDGF indirectly stimulated SMC motility, perhaps by inducing TSP synthesis. Thus, TSP could function as an autocrine motility factor for SMC. In order to establish whether this mechanism was feasible, we assessed PDGF-mediated motility in the presence of either mAb C6.7 or cycloheximide. SMC preincubated with $\mathrm{mAb} \mathrm{C6.7}$ were unable to migrate in response to PDGF (Fig. 8a). Inhibition was dose dependent with migration reduced to background levels in the presence of $200 \mu \mathrm{g} / \mathrm{ml} \mathrm{mAb} \mathrm{C6.7.} \mathrm{Alternately,} \mathrm{SMC} \mathrm{were} \mathrm{prein-}$ cubated with $10 \mu \mathrm{g} / \mathrm{ml}$ cycloheximide to inhibit the induction of TSP synthesis following exposure to PDGF. Cycloheximide-treated SMC were assayed for migration to either TSP or PDGF (Fig. 8b). Chemotaxis to PDGF was dramatically inhibited, $P<0.01$, in the presence of cycloheximide. Furthermore, chemotaxis in response to TSP was also reduced in cycloheximidetreated SMC, $P<0.05$, but to a much lesser extent. These experiments indicated that cell surface-associated TSP is essential for SMC chemotaxis to PDGF, and that PDGF stimulates SMC motility indirectly, through induction of TSP expression which serves as an autocrine motility factor

\section{DISCUSSION}

A critical event in the early stages of atherosclerotic lesion development is the migration of SMC from the media into the intima of the blood vessel wall. In the present study, we investigated the role of TSP in SMC migration and found that TSP was a potent mediator of SMC migration. In comparison with concentrations of bFGF or PDGF-BB which resulted in maximal levels of migration, TSP elicited a $40 \%$ greater migratory response. Of particular interest was the finding that suboptimal concentrations of TSP potentiated SMC migration to PDGF. SMC migration to the combination of TSP and PDGF was greater than the maximal response observed to PDGF alone, suggesting that interactions of growth factors with ECM molecules may accelerate responses initiated by one or the other. Further investigation demonstrated that TSP is an autocrine motility factor for vascular SMC and is essential for PDGFmediated motility. The availability of TSP at sites of vascular damage and inflammation, both kinetically and spatially, correlates with early events after injury (Raugi et al., 1990; Botney et al., 1992) and suggests that TSP may be an important modulator of these processes. Furthermore, since PDGF expression is also an early response to vascular injury (Walker et al., 1986), these results emphasize the complex interactions that can be expected to influence SMC behavior following vascular damage.

The interaction of TSP with SMC has been previously studied with respect to proliferation (Majack et al., 1986, 1988). TSP was demonstrated to be essential for SMC proliferation in response to PDGF, an effect presumably involving the HBD since heparin was inhibi- 


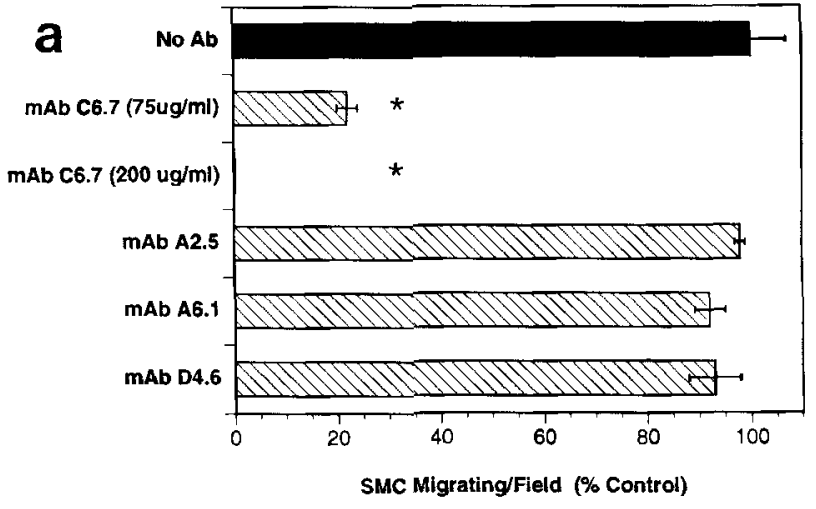

Fig. 7. TSP potentiation of SMC migration to PDGF is inhibited by anti-TSP mAb C6.7. a: mAb C6.7 inhibition of TSP potentiation of PDGF-mediated SMC migration is dose dependent. b: TSP proteolytic fragments are not able to potentiate SMC migration to PDGF. SMC $\left(3 \times 10^{4} /\right.$ well) were placed into the upper wells of modified Boyden chambers. TSP was preincubated in the presence or absence of antiTSP mAbs ( $200 \mu \mathrm{g} / \mathrm{ml}$ except as indicated) for 30 minutes at $37^{\circ} \mathrm{C}$ before being added to the lower wells of the chamber along with PDGF $(10 \mathrm{ng} / \mathrm{ml})$. Alternatively, PDGF $(10 \mathrm{ng} / \mathrm{ml})$ and TSP or TSP prote-

tory. In contrast, we have shown that the HBD plays a facilitative rather than essential role in mediating SMC migration. The $140 \mathrm{kD}$ domain mediated SMC migration to intact TSP, as shown by inhibition in the presence of mAb C6.7, but its potency was halved when migration was assessed to $140 \mathrm{~K}$ alone. Only when the HBD and $140 \mathrm{~K}$ were combined did SMC migration reach levels seen with intact $T S P$. These results suggested that the HBD does not directly mediate SMC migration, but facilitates migration, perhaps by influencing the conformation of $140 \mathrm{~K}$. The importance of conformation in TSP-mediated SMC migration was further supported by studies involving anti-TSP mAbs and heparin. Heparin by itself only slightly inhibited SMC migration to either intact TSP or 140K. mAb C6.7 also partially inhibited SMC migration to $140 \mathrm{~K}$. However, heparin in conjunction with mAb C6.7 inhibited migration to $140 \mathrm{~K}$ almost completely. These results suggest that a conformationally sensitive site on the $140 \mathrm{kD}$ fragment, possibly the secondary heparin-binding site lying within the type I repeats of TSP (Guo et al., $1992 \mathrm{a}, \mathrm{b})$, binds heparin and plays a role in SMC migration. Exposure of a cryptic heparin-binding site within the $140 \mathrm{~K}$ fragment upon proteolytic cleavage has been previously observed, and may have physiological implications since cellular responses to intact vs. proteolyzed matrix proteins are often distinct (Guo et al., 1992a; Chelberg et al., 1989). Although the evidence argues against a role for the HBD interacting with heparan sulfate proteoglycans in mediating SMC migration, the data suggest that cell surface proteoglycans may interact with the heparin-binding site in $140 \mathrm{~K}$. Interestingly, heparin inhibits TSP-mediated potentiation of SMC proliferation to EGF and shifts TSP localization from the SMC cell surface into the media (Majack et al., 1986,1988 ). Such modulation of TSP expression patterns, rather than inhibiting SMC motility, could accelerate SMC migration by raising concentrations of soluble TSP in areas surrounding injured endothelium.

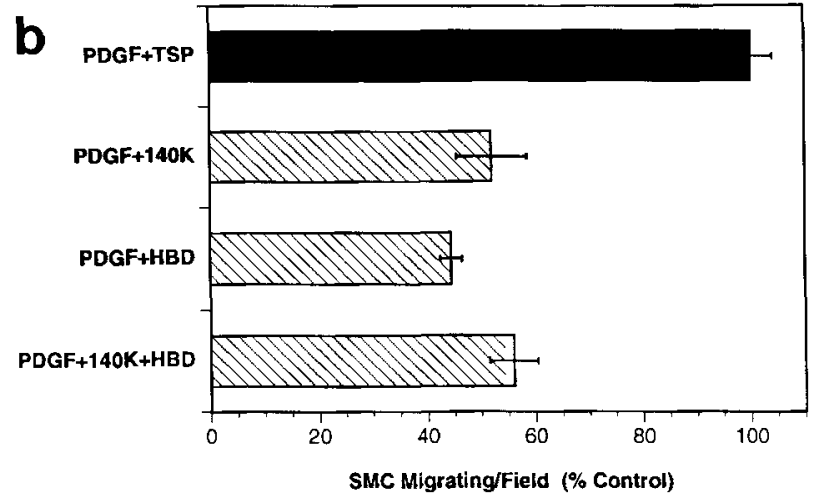

olytic fragments $(50 \mathrm{nM})$ were added to the lower wells. Assays were carried out for 6 hours at $37^{\circ} \mathrm{C}$. The number of migrating $\mathrm{SMC}$ was scored as described in Materials and Methods with triplicate filters prepared for each treatment. Five high power $(\times 400)$ fields were scored for each filter and values shown represent the mean $\%$ control \pm S.E.M. Control values represent SMC migration to the mixture of PDGF and 50 nM TSP; 105.1 $\pm 8.8 \mathrm{SMC} / 400 \times$ field in a, and $106.8 \pm 10.0 \mathrm{SMC} / 400 \times$ field in $\mathrm{b} .{ }^{*} P<0.005$.

Thus, TSP could differentially affect SMC responses depending on changes in TSP-SMC association and TSP functional domains involved.

Adhesion of SMC to TSP is mediated through the $\alpha_{\mathrm{v}} \beta_{3}$ vitronectin receptor (Lawler et al., 1988). We have demonstrated a role for an $\alpha_{\mathrm{v}}$-containing integrin, but not $\alpha_{v} \beta_{3}$, in SMC migration to TSP. Lack of inhibition of SMC migration with either $\beta_{1}$ or $\beta_{3}$ antibodies suggested that the SMC receptor mediating migration is neither the $\alpha_{v} \beta_{3}$ receptor involved in SMC adhesion (Lawler et al., 1988) nor the $\alpha_{\mathrm{v}} \beta_{1}$ receptor involved in adhesion of epithelial cells to vitronectin (Bodary and McLean, 1990). Neurite outgrowth of embryonic chick retinal neurons on TSP was inhibited by antibodies to $\alpha_{\mathrm{v}}$ (Neugebauer et al., 1991), implicating $\alpha_{\mathrm{v}}$-containing integrins in this specialized form of migration. Overall these data indicate the presence of multiple functional receptors on SMC surfaces that interact with TSP, including heparan sulfate proteoglycans in TSP-dependent SMC proliferation and $\alpha_{\mathrm{v}}$ integrins in TSP-mediated SMC motility.

Although the effects of PDGF on SMC migration have been extensively studied, little is known about the interaction of growth factors with accessory molecules important in cell migration, such as components of the ECM. Expression of TSP and PDGF at sites of vascular injury is linked both functionally and temporally. PDGF treatment of SMC stimulates a rapid, though transient, rise in TSP expression (Majack et al., 1985), and TSP can also be derived from activation of platelets, monocytes, fibroblasts, and endothelial cells (Mosher, 1990). Sources of PDGF include activated platelets, monocytes, endothelial cells, and SMC themselves (Ross, 1986). Both TSP and PDGF are expressed by similar cell types, and with similar kinetics after cell activation, thus leading to their colocalization at sites of vascular damage. Based on this evidence, we investigated the effect of suboptimal concentrations of TSP on PDGF-mediated SMC migration. Our data support a 

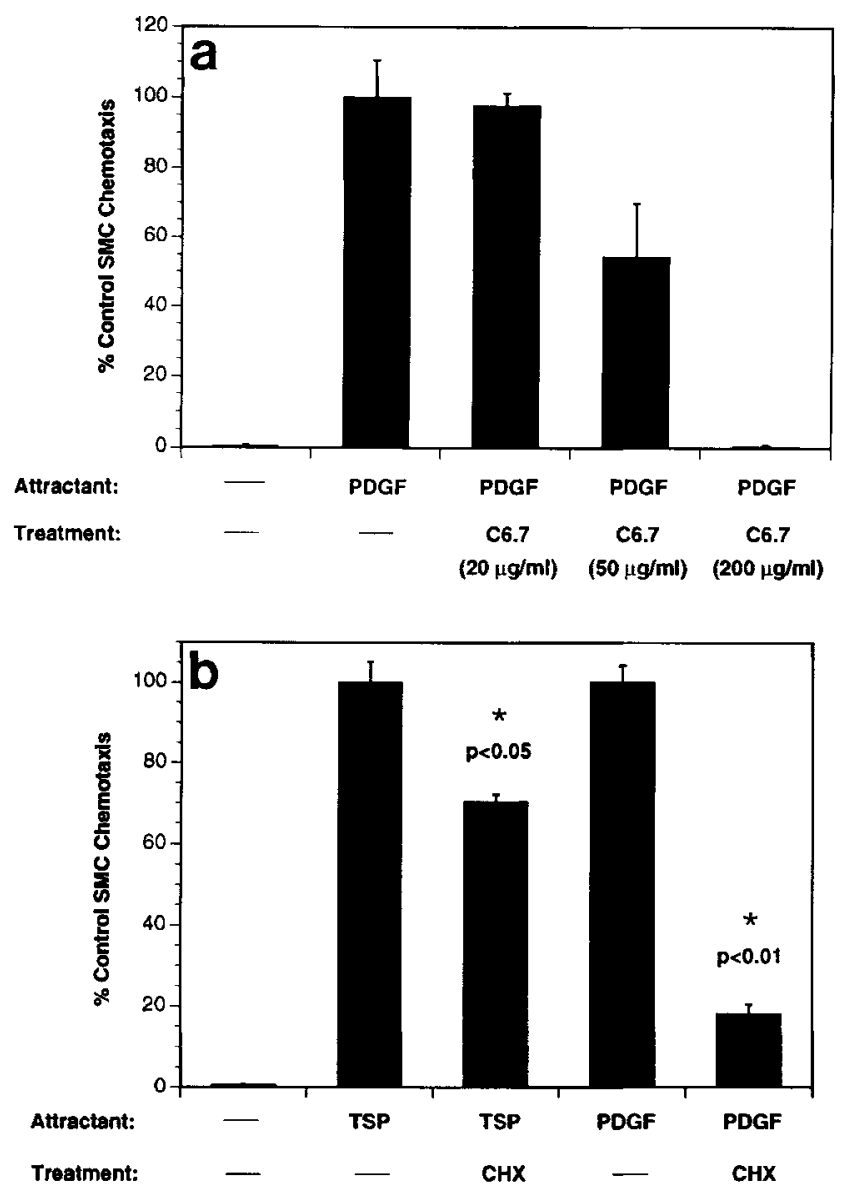

Fig. 8. TSP synthesis and cell surface association are essential for SMC migration to PDGF, a: Anti-TSP mAb C6.7 inhibited SMC chemotaxis to PDGF. b: Treatment of SMC with cycloheximide (CHX) inhibited SMC chemotaxis to PDGF. SMC were preincubated with either mAb C6.7 (30 minutes, concentration as indicated) or cycloheximide ( 16 hours, $10 \mu \mathrm{g} / \mathrm{ml}$ ) before being placed into the upper wells of the chemotaxis chamber. In addition, mAb C6.7 or cycloheximide was present throughout the assay. TSP $(1 \mu \mathrm{M})$ or PDGF $(0.3 \mathrm{nM})$, as indicated, was placed into the lower wells and the chamber was incubated for 6 hours at $37^{\circ} \mathrm{C}$. The number of migrating SMC was scored in triplicate as described in Materials and Methods. Five high power $(\times 400)$ fields were scored for each filter and values represent the mean \% control \pm S.E.M.

role for TSP in the potentiation of PDGF-mediated migration. The effect was dose dependent, specific for TSP, and mediated by a site in the $140 \mathrm{kD}$ domain. Maximal potentiation was observed between 50 and $100 \mathrm{nM}$ TSP, a log-fold lower than the concentrations necessary for maximal stimulation of SMC migration by TSP alone. Additionally, $50 \mathrm{nM}$ TSP has been shown to stimulate $\mathrm{S}_{6}$ kinase and phosphatidylinositol turnover in SMC (Scott-Burden et al., 1988), indicating that TSP elicits physiologically relevant responses within this concentration range.

SMC migration to the combination of TSP and PDGF was completely inhibited by mAb C6.7, an unlikely result if TSP and PDGF were acting independently. Alternate scenarios include a functional linkage between TSP and PDGF receptors on the SMC surface or a specific bimolecular complex formed by TSP and PDGF. Raines et al. (1992) demonstrated binding of PDGF to the ECM protein SPARC which inhibited PDGF binding to its receptor, but failed to detect PDGF binding to TSP under similar conditions. We investigated the possible interaction of TSP with PDGF by determining if radiolabeled TSP coimmunoprecipitated with PDGF, and found no evidence for a specific interaction (data not shown). Therefore, we took two alternate approaches in elucidating a mechanism for potentiation of SMC chemotaxis in the presence of both PDGF and TSP. Since anti-TSP mAbs have been shown to disrupt the association of TSP with the SMC surface (Majack et al., 1988), we preincubated SMC with $\mathrm{mAb}$ C6.7 before assessing migration to PDGF. In the presence of $\mathrm{mAb}$ C6.7, SMC were unable to migrate to PDGF, indicating that cell surface-associated TSP is critical in this process. Additionally, it was evident that PDGF would induce de novo TSP synthesis during the 6 hour assay period (Majack et al., 1987). By using cycloheximide to inhibit de novo protein synthesis, we investigated the importance of TSP in SMC motility to PDGF. Our results demonstrated that TSP is an essential autocrine motility factor for SMC; i.e., PDGF stimulates motility indirectly through the induction of TSP synthesis. Thus, inhibition of either TSP synthesis or TSP-SMC interactions resulted in a diminished SMC migratory response. Although the combination of PDGF-AA and $\mathrm{bFGF}$ has been demonstrated to potentiate SMC proliferation (Majack et al., 1990), the mechanism of action involved remains unclear. Similarly, the pathway(s) through which TSP facilitates EGF-dependent SMC proliferation (Majack et al., 1986) has not been identified. Overall, the potentiation of growth factor-mediated functional responses by TSP, such as SMC migration and proliferation, reinforces the autocrine nature of TSP's interactions with SMC.

Recently, a more comprehensive picture of the role of TSP in SMC behavior has begun to emerge. No longer defined only as a component of the ECM, TSP has been shown to exert pleiotropic effects on SMC. First, TSP is an immediate-early response gene activated following PDGF treatment of SMC (Majack et al., 1987). Second, TSP promotes adhesion of SMC (Lawler et al., 1988). Third, TSP functions as an autocrine growth factor, potentiating EGF- and PDGF-mediated SMC proliferation (Majack et al., 1986, 1988). Fourth, we have demonstrated that TSP is a potent modulator of SMC migration and is essential in SMC migration to PDGF. In vivo, TSP has been localized to atherosclerotic plaques, regions of SMC migration and proliferation (Botney et al., 1992; Wight et al., 1985). Furthermore, evidence that endothelial cell adhesion and proliferation are inhibited by TSP (Lahav, 1988; Bagavandoss and Wilks, 1990 ) suggests that TSP may play a dual role in atherosclerosis; promoting SMC adhesion, migration, and proliferation in the vascular intima while preventing endothelial cells from doing the same. Thus, TSP influences several aspects of SMC physiology important in the early events preceding the development of an atherosclerotic lesion. By understanding the molecular switches controlling these pathways in greater detail, the molecular targets most amenable to early and effective therapeutic intervention can be identified. 


\section{ACKNOWLEDGMEN'TS}

The authors wish to thank the many investigators for their generous gifts of antibodies. We would also like to thank Drs. Kay Broschat and Vishva Dixit for many invigorating discussions, advice, and for reading the manuscript. This work was supported in part by grants from the AHA-Michigan (27G912, R.Y.) and NIH (AI26863, S.J.S.; HL21568, HL44204, U.S.R.).

\section{LITERATURE CITED}

Asch, A.S., Barnwell, J., Silverstein, R.L., and Nachman, R.L. (1987) Isolation of the thrombospondin membrane receptor. J. Clin. Invest. 79:1054-1061.

Bagavandoss, P., and Wilks, J.W. (1990) Specific inhibition of endothelial cell proliferation by thrombospondin. Biochem. Biophys. Res. Commun., 170:867-872

Bodary, S.C., and McLean, J.W. (1990) The integrin beta 1 subunit associated with the vitronectin receptor alpha $v$ subunit to form a novel vitronectin receptor in a human embryonic kidney cell line. J. Biol. Chem., 265:5938-5941.

Botney, M.D., Kaiser, L.R., Cooper, J.D., Mecham, R.P., Parghi, D. Roby, J., and Parks, W.C. (1992) Extracellular matrix protein gene expression in atherosclerotic hypertensive pulmonary arteries. Am. J. Pathol., 140:357-364.

Chamley-Campbell, J.H., Campbell, G.R., and Ross, R. (1981) Phenotype-dependent response of cultured aortic smooth muscle to serum mitogens. J. Cell Biol, , 89:379-383.

Chelberg, M.K., Tsilibary, E.C., Hauser, A.R., and McCarthy, J.P. (1989) Type IV collagen-mediated melanoma cell adhesion and migration: Involvement of multiple, distinct domains of the collagen molecule. Cancer Res., 49:4796-4802.

Cheresh, D.A., and Spiro, R.C. (1987) Biosynthetic and functional properties of an Arg-Gly-Asp-directed receptor involved in human melanoma cell attachment to vitronectin, fibrinogen, and von Willebrand factor. J. Biol. Chem., 262:17703-17711.

Clowes, A.W., and Clowes, M.M. (1986) Kinetics of cellular proliferation after arterial injury: IV. Heparin inhibits rat smooth muscle mitogenesis and migration. Circ. Res., 58:839-845.

Dixit, V.M., Grant, G.A., Santoro, S.A., and Frazier, W.A. (1984) Isolation and characterization of a heparin-binding domain from the amino terminus of platelet thrombospondin. J. Biol. Chem., 259:10100-10105.

Dixit, V.M., Galvin, N.J., O'Rourke, K.M., and Frazier, W.A. (1986) Monoclonal antibodies that recognize calcium-dependent structures of human thrombospondin. J. Biol. Chem., 261:1962-1968.

Grotendorst, G.R., Chang, T., Seppa, H.E.J., Kleinman, H.K., and Martin, G.R. (1982) Platelet-derived growth factor is a chemoattractant for vascular smooth muscle cells. J. Cell. Physiol., 113:261266.

Guo, N., Krutzsch, H.C., Nègre, E., Vogel, T., Blake, D.A., and Roberts, D.D. (1992a) Heparin-and sulfatide-binding peptides from the type I repeats of human thrombospondin promote melanoma cell adhesion. Proc. Natl. Acad. Sci. USA, 89:3040-3044.

Guo, N., Krutzsch, H.C., Nègre, E., Zabrenetzky, V.S., and Roberts, D.D. (1992b) Heparin-binding peptides from the type I repeats of thrombospondin. Structural requirements for heparin binding and promotion of melanoma cell adhesion and chemotaxis. J. Biol. Chem., 267:19349-19355.

Hedin, U., Bottger, B.A., Forsberg, E., Johansson, S., and Thyberg, J. (1988) Diverse effects of fibronectin and laminin on phenotypic properties of cultured arterial smooth muscle cells. J. Cell Biol. 107:307-319.

LaBell, T.L., McGookey Milewicz, D.J., Disteche, C.M., and Byers, P.H. (1992) Thrombospondin II: Partial cDNA sequence, chromosome location, and expression of a second member of the thrombospondin gene family in humans. Genomics, 12:421-429.

Lahav, J. (1988) Thrombospondin inhibits adhesion of endothelial cells. Exp. Cell Res., 177:199-204.

Lawler, J. (1986) The structural and functional properties of thrombospondin. Blood, 67:1197-1209.

Lawler, J., Weinstein, R., and Hynes, R.O. (1988) Cell attachment to thrombospondin: The role of arg-gly-asp, calcium, and integrin receptors. J. Cell Biol., 107:2351-2361.

Majack, R.A., Cook, S.C., and Bornstein, P. (1985) Platelet-derived growth factor and heparin-like glycosaminoglycans regulate throm- bospondin synthesis and deposition in the matrix by smooth muscle cells. J. Cell Biol., 101:1059-1070.

Majack, R.A., Cook, S.C., and Bornstein, P. (1986) Control of smooth muscle cell growth by components of the extracellular matrix: Autocrine role for thrombospondin. Proc. Natl. Acad. Sci. USA, 83:90509054.

Majack, R.A., Mildbrandt, J., and Dixit, V.M. (1987) Induction of thrombospondin messenger RNA levels occurs as an immediate primary response to platelet-derived growth factor. J. Biol. Chem., 262:8821-8825.

Majack, R.A., Goodman, L.V., and Dixit, V.M. (1988) Cell surface thrombospondin is functionally essential for vascular smooth muscle cell proliferation. J. Cell Biol., 106:415-422.

Majack, R.A., Majesky, M.W., and Goodman, L.V. (1990) Role of PDGF-A expression in the control of vascular smooth muscle cell growth by transforming growth factor- $\beta$. J. Cell Biol., 111:239-247.

Mansfield, P.J., Boxer, L.A., and Suchard, S.J. (1990) Thrombospondin stimulates motility of human neutrophils. J. Cell Biol., 111:3077-3086.

Mosher, D.F. (1990) Physiology of thrombospondin. Annu. Rev. Med, 41:85-97.

Murphy-Ullich, J.E., Schultz-Cherry, S., and Höök, M. (1992) Transforming growth factor- $\beta$ complexes with thrombospondin. Mol. Biol. Cell, 3:181-188.

Naito, M., Hayashi, T., Kuzuya, M., Funaki, C., Asai, K., and Kuzuya, F. (1989) Fibrinogen is chemotactic for vascular smooth muscle cells. FEBS Lett., 247:358-360.

Naito, M., Hayashi, T., Funaki, C., Kuzuya, M., Asai, K., Yamada, K., and Kuzuya, F. (1991) Vitronectin-induced haptotaxis of vascular smooth muscle cells in vitro. Exp. Cell Res., 194:154-156.

Neugebauer, K.M., Emmett, C.J.. Venstrom, K.A., and Reichardt, L.F. (1991) Vitronectin and thrombospondin promote retinal neurite outgrowth: Developmental regulation and role of integrins. Neuron, 6:345-358.

Raines, E.W., Lane, T.F., Iruela-Arispe, M.L., Ross, R., and Sage, E.H. (1992) The extracellular glycoprotein SPARC interacts with platelet-derived growth factor (PDGF)-AB and -BB and inhibits the binding of PDGF to its receptors. Proc Natl Acad Sci USA 89:1281-1285.

Raugi, G.J., Mullen, J.S., Bark, D.H., Okada, T., and Mayberg, M.R. (1990) Thrombospondin deposition in rat carotid artery injury. Am. J. Pathol, 137:179-185.

Ross, R. (1986) The pathogenesis of atherosclerosis. An update. N. Engl. J. Med., 314:488-500.

Ross, R., Raines, E.W., and Bowen-Pope, D.F. (1986) The biology of platelet-derived growth factor. Cell, 46:155-169.

Ryan, U.S., and Maxwell, G. (1992) Isolation, culture, and subculture of bovine pulmonary artery endothelial cells: Mechanical methods. J. Tissue Culture Methods, 10:3-5.

Sato, Y., Hamanaka, R., Ono, J., Kuwano, M., Rifkin, D.B., and Takaki, R. (1991) The stimulatory effect of PDGF on vascular smooth muscle cell migration is mediated by the induction of endogenous basic FGF. Biochem. Biophys. Res. Commun., 174:12601266 .

Scott-Burden, T., Resink, T.J., Baur, U., Burgin, M., and Buhler, F. (1988) Activation of $S_{6}$ kinase in cultured vascular smooth muscle cells by submitogenic levels of thrombospondin. Biochem. Biophys. Res. Commun., 150:278-286.

Shekhonin, B.V., Domogatsky, S.P., Idelson, G.L., Koteliansky, V.E. and Rukosuev, V.S. (1987) Relative distribution of fibronectin and type I, III, IV, V collagens in normal and atherosclerotic intima of human arteries. Atherosclerosis, 67:9-16.

Taraboletti, G., Roberts, D.D., and Liotta, L.A. (1987) Thrombospondin-induced tumor cell migration: Haptotaxis and chemotaxis are mediated by different molecular domains. J. Cell Biol., 105:2409 2415 .

Walker, L.N., Bowen-Pope, D.F., Ross, R., and Reidy, M.A. (1986) Production of platelet-derived growth factor-like molecules by cultured arterial smooth muscle cells accompanies proliferation after arterial injury. Proc. Natl. Acad. Sci. USA, 83:7311-7315.

Wight, T.N., Raugi, G.J., Mumby, S.M., and Bornstein, P. (1985) Light microscopic immunolocation of thrombospondin in human tissues. J. Histochem. Cytochem., 33:295-302.

Yabkowitz, R., and Dixit, V.M. (1991) Human carcinoma cells express receptors for distinct domains of thrombospondin. Cancer Res., 51:1645-1650

Yabkowitz, R., Mansfield, P.J., Dixit, V.M., and Suchard, S.J. (1993) Motility of human carcinoma cells in response to thrombospondin Relationship to metastatic potential and thrombospondin structural domains. Cancer Res., 5.3:378-387. 